\title{
Features of the application of art-therapeutic and gaming technology based on folk music in rehabilitation and socialization of children with health limitations
}

\author{
Natalia Ivanovna Anufrieva*, Aleksandr Vlavlenovich Kamenets, Marina Viktorovna Pereverzeva, Marina Gennadievna Kruglova
}

Department of Sociology and Philosophy of Art, Russian State Social University, Wilhelm Pieck Street, 4/1, Moscow 129226, Russia

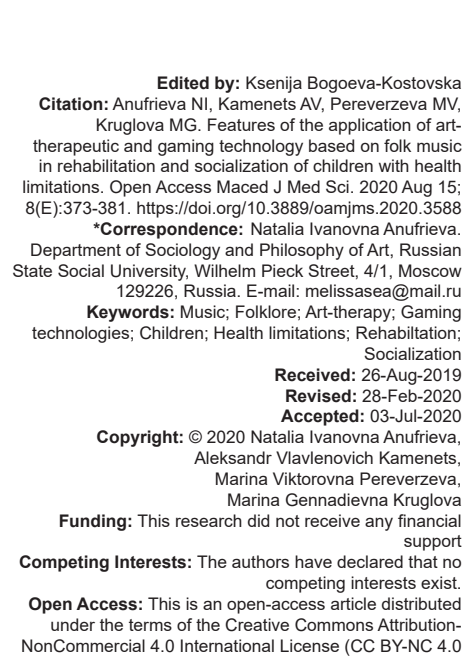

\section{Introduction}

In recent decades, the number of newborns with health problems and pathologies associated with the nervous system development has been growing steadily. Therefore, the problem of helping such children, their rehabilitation, and socialization is becoming one of the most urgent problems in pedagogy.

The sustainable development of society largely depends on how broad is the conditions, created by the state for the realization of the intellectual and creative potential of all citizens, how active and productive are the life of people in the country, including those with health limitations. In correcting the problems of children with health limitations, the most effective are methods of pedagogical assistance, such as behavioral therapy, occupational (ergotherapy), various types of art therapy (including music), adaptive physical education, occupational therapy (training through manual labor), gaming technology, etc.

Different countries of the world have their own schools of art therapy. The Russian school was founded by A. Kopytin, Ph.D. in Medical Sciences. According to him, the purpose of art therapy in education is to preserve or restore the health of trainees and their adaptation to the conditions of the educational institution through the implementation of psychocorrectional, diagnostic, and psycho-prophylactic abilities, as well as to develop certain psychological and personal qualities of trainees [1]. The followers of this school summarized the experience of using art as a means of integrated educational, developmental, and correctional impact on children with hearing, vision, and speech problems, mental retardation, behavioral disorders, mental subnormality, and disorders of the 
musculoskeletal system. Scientists consider art therapy as a set of techniques based on the use of different types of art that allows carrying out psycho-correction by stimulating artistic and creative manifestations.

Singing has a positive effect on health through vibrations that stimulate the work of internal organs, which partially absorb sound waves due to resonance [2]. Through vocal exercises, one can influence the psychoemotional background, muscle tone, and other conditions of the child, because the voice is a component of various psychophysiological processes occurring in the body. Respiratory therapy also heals children [3]. It includes playing wind instruments, breathing exercises to the music, training of the respiratory function of the body, contributing to muscle and psychological relaxation, removal of internal tension, and achieving a sense of psychological and physical looseness [4], [5], [6], [7].

Psychologists and neuroscientists have noted the toning effect of the regular musical rhythm and increasing positive emotional state while singing. Emotions caused by music affect the change in pulse, breathing, speed, response, and muscle strength. Music regulates the emotional sphere of the person, whose reduction leads to the weakening of the immune system. Music can have a therapeutic effect on children with behavioral and communication disorders, visual impairment, speech dysfunctions, and mental retardation. Musical works, different in their emotionalfigurative content, normalize biochemical processes, affecting the human body through emotions [8]. Art-therapeutic technology is used to overcome psychological problems and to develop emotional perception necessary for the development of creative abilities (emotional, artistic, and heuristic orientation), the formation of an effective and practical sphere (applied orientation), and orientation to the development of the personality of a trainee with health limitations (psychological and pedagogical orientation).

Folk therapy, which has a long tradition, is also used in musical practice. Folk songs and tunes were an integral part of the ancient festive and ritual culture, which integrated different types of artistic and creative activities. Immanent capabilities of folklore, such as the collective nature of creativity and improvisation, contribute to the regulation of interpersonal communication, the development of individual creative abilities of the child, his spiritual values, ethical ideals, social experience, and norms of behavior. The folklore reflects the forms of interaction of the individual with nature and society, guaranteeing the preservation of physical and mental health of personality. A small rhyme or song, understandable and interesting for the child, helps children grow up healthy, jokes and nursery rhymes made them fun, lullabies soothed, other songs taught them the goodness, wisdom, love of nature, family, and native land. Folk art forms human qualities, such as sincerity, charm, and openness, which, combined with skills and professionalism, contribute to the full life of the individual.
Among the rehabilitation tools of children with health limitations, classes in musical folklore in general and singing, in particular, occupy a central place. As a rule, children tend to love music because it gives them pleasure on an unconscious level. They are much more likely to engage in music-playing creativity than in any other activity. Even passive listening to music has a positive effect [9]. Training based on musical folklore is an intense process since it involves a lot of body functions and establishes the necessary connections between the neurons of the brain. Creative activity is inseparable from healthy development and human activity in the course of cognition, development, and transformation of the world and oneself [10]. The creative activity reveals the intellectual potential of the individual, who implements both innate and acquired abilities and skills.

\section{Literature Review}

The interaction of music and medicine is one of the challenging scientific problems considered at the intersection of musicology, cultural studies, and psychology. The situation, in which man and nature found themselves in modern man-made civilization, as well as the crisis of religious life, spirituality, and morality in society in general, forced to turn to the primordial traditions and forms of life-sustaining activity. One type of these processes regulation is music therapy, which shows a universal approach to a man in unity and the relationship of his spiritual and physical components. Scientists have found that music has a vibrational, physiological, and mental impact on many areas of human activity [1], [3], [11]. Sound vibrations can stimulate metabolic processes in the body at the cellular level and improve the respiratory, motor, and cardiovascular systems of the body. Playing wind instruments help to strengthen and improve the respiratory system, while the keyboard instrument can help a child with weak motor skills of fingers.

The specificity of the problem discussed in work required the study of various literature on musical education (Gudina, Yudovina-Galperina, and Tishina); musical therapy (Alvin and Warwick, DeckerVoigt, Kopytin, Kotysheva, Nektu, Petrushin, VladichMandarich and Plosko, and Davydova); works of speech defectologists (Boromykova and Rybakov); studies on neurology and neuropsychology, including those directly related to music (Permyakova and Tkachenko, Glozman and Pavlov); autism and methods of working with autistic children (Greenspan and Weeder, Bharathi, Brown, Edgerton, Johnston, Marom, Sharda, Taheri, Thompson, and Woodward); folklore and its pedagogical potential (Vinogradov and Ovsyannikova); as well as teaching children with health limitations in general (Korolkova, Lazarev, and Perkins School). 
Each of these areas has been developed and studied in sufficient detail, but the works arising at the intersection of these areas, are quite a few. Alvin and Warwick [18] and Kotysheva [5] suggest using music therapy as a psychological correction. Early inclusion of children with health limitations in music classes is necessary because such classes can be used "as a way of emotional impact on children to correct their physical and mental disabilities, as a way of nonverbal communication, and as well as one of the possible ways of knowing the world" [5]. The purpose of classes with small groups of children is to stimulate the development of the emotional sphere of children; improve the quality of communication; and promote self-regulation. Teachers consider a well-built structure of the lesson to be a prerequisite for the success of music therapy, which is an absolute necessity when working with autistic children.

A method of language forming system developed by Novikova-Ivantsova is at the junction of music therapy and speech therapy. It differs from others by the presence of elements of musical vocal therapy. The author offers a lot of exercises to develop fine motor skills, attention, and to overcome speech therapy problems. "Starting speech" in children with delayed psycho-verbal development occurs in the course of singing. The child sings vowels and consonants, then syllables, gradually approaching the vocalization of the full text of the song. A significant place in this technique is also occupied by listening to music, mostly folk songs in the native language (especially effective is listening if the child's mother sings). Johnston et al. 2018 [13] also hold this viewpoint. As noted in their study, "fundamental elements of music have been shown form social relationships and promote cognitive progression," and also "motivate children to interact differently with their environment through providing novel and engaging approaches to music interaction and creativity" [13].

Renowned teacher Yudovina-Halperina also worked with children with health limitations, including autism. She revealed a deep connection between the specific musical problems experienced by some children and the problems of their speech: "If the child does not pronounce the letters, if his speech is interrupted by frequent uneven breathing, and if he does not know how to build a phrase, than failures, stammering, and shortness of breath will be in his musical speech as well. That is, musical and verbal language are deeply related in some things" [14].

Since the problem of teaching children with health limitations is becoming more and more urgent, and the work that comprehensively reveals the problem is not enough, it requires a special study, primarily based on the evaluation of the results of practical art therapeutic experience. Theoretical understanding of the problem makes it possible to identify the conditions, while pedagogical experiment allows testing the effectiveness of art therapy and gaming technologies, as well as features of their application in the rehabilitation and socialization of children with health limitations based on musical folklore. The specifics of the considered technologies are covered in part in the work of Davydova et al. 2018 [15] and Ovsyannikova et al., 2018 [16].

Thus, the works of scientists consider mainly the emotional impact of music on children with health limitations and change in their mental condition in the course of lessons, while the development of specific cognitive, communicative, or physical abilities due to the impact on children of art therapy methods was beyond a comprehensive study. The reasons for intensive rehabilitation and socialization of children with health limitations in the course of musical folklore studies have not been studied before.

\section{Research Hypothesis}

Musical art therapeutic technologies aimed at overcoming psychological problems and the development of emotional perception of children is widely used in the world pedagogical practice. However, music is able to do more; it can enhance the development of communicative and cognitive abilities in children with delayed psycho-verbal development and autistic children, which is proved by the conducted study. Learning music is as intense process as learning to read, write, and count. That is why music classes based on children's folklore are one of the most effective tools in correcting the problems of children with health limitations. Learning music requires the constant attention of children, it instills interest and hard work, patience, and perseverance sets on perfecting his personality. Music is one of the alternative communication systems. Education on the basis of children's folklore becomes especially fruitful since it is directly related to playing, creativity, speech, and singing - very similar processes, whose emotional content stimulates the active development of the child.

Researchers and practitioners, when assessing the game as a complex, multifaceted pedagogical phenomenon, as a method of training and education of children, as a form of their training, and as a means of the harmonious development of the child's personality, emphasize that the game situations created by the teacher should be aimed at the development of involuntary attention of children and the formation of skill set of social adaptation and successful socialization in the environment. As the plot of the game, the teachermentor should use the real-life situation or refer to the problem that can be borrowed from the folk tale, traditional ritual, or calendar holiday. This is due to the fact that the folk game, its essence, and purpose stem from the relations common in the surrounding reality 
as the most important source of social experience. In the assessment of the greatest researcher of children's folklore Vinogradov, the game is defined as "the result of the manifestation of folk pedagogy in the life" [17].

In the course of game situations, especially created by the teacher, and based on the storylines of traditional folklore, a child with different nosologies forms actively communicative and cognitive skills, deepens the previously acquired knowledge, strengthens skills needed in various spheres of lifesustaining activity (cognitive, communicative, artistic, and esthetic). Playing activities based on the traditional folklore create conditions for the acquisition of vital skills with greater effectiveness than using the method of direct training.

The Russian national games directly influence the process of development of mental qualities, will, character, moral attributes and physical condition of the child, and also formation of motivation to occupations by creative activity.

\section{Methods}

Identifying features of art-therapeutic and game technologies based on musical folklore in the rehabilitation and socialization of children with health limitations, and assessment of the results of these processes can be carried out in the course of psychopedagogical experiment and practical experience of working with children with health limitations that allow drawing conclusions about the effectiveness of the application of advanced teaching methods. First of all, the authors studied the results of the application of the method based on music therapy developed by Warwick and Alvin 2008 [18], Boromykova 1999 [11], and Nektu 2001 [19]; music-based psychological correction developed by Kotysheva 2009 [5], Permyakova and Tkachenko 2016 [20]; musical correction of autistic children developed by Greenspan and Weeder 2013 [6], Bharathi et al., 2019 [21], Brown 1994 [22], Edgerton 1994 [12], Johnston et al., 2018 [13], Marom et al., 2018 [23], Sharda et al., 2018 [24], Taheri et al., 2019 [25], Thompson and Elefant 2019 [26], VladićMandarić and Plosko 2017 [27], and Woodward 2004 [28]; and musical lessons of Udovina-Galperina 2002 [14], as well as lessons of developmental music in the famous "Perkins school" [29].

The specificity of the problems considered in work also determined the choice of research methods due to the difficulties faced by both children and teachers caused by limited health condition. Therefore, the authors of the present study selected analysis and synthesis of theoretical and methodological material, best practices of readaptation and socialization of children, psychological and pedagogical observation and testing, modeling, and forecasting of the educational process, psychological and pedagogical experiment, and psycho-correction practice of children with mental retardation and autism, as well as comparison of empirical data.

The empirical study included the diagnosis of problems of children with delayed psychoverbal development and early childhood autism, methodological development of a set of developmental exercises, practical training, and retesting to assess learning outcomes. Pedagogical experiment on the use of art-therapeutic and gaming technologies was carried out in the Koptevo Center for Social Aid to Family and Children (Moscow), where children with disorders of the musculoskeletal system, delayed psychoverbal development (DPVD), and autism undergoes the rehabilitation and socialization. The study involved four children:

Polina S., 13 years old, hydrocephalus, DPVD, autophobia manifestations;

Ilya V., 12 years old, early childhood autism, uses speech, which is associated with strong echolalia, often builds grammatical structures incorrectly, speaks about himself in the third person;

Farida A., 12 years old, a mild form of DPVD;

Artem L., 9 years old, early childhood autism, speech is missing, a lot of motor stereotypes.

The results of art-therapeutic and musicplaying sessions with four children of the Rehabilitation Center suffering from DPVD and autism were evaluated by communicative and cognitive qualities, such as:

Productive activity time

Ability to concentrate

Attentional set-shifting

Speech development

Understanding spoken language

The ear for music

Timekeeping

Accuracy of intonation

Ability to play musical instruments

Precision movements to the music.

The assessment was carried out by observation during the trial lesson, which included acquaintance, the conversation about songs, dances, instruments, simple tasks to sing a favorite song, repeat the melody, perform the song together with the teacher, clap the rhythm, move to the music, etc. For each expressed quality was given one point. In general, the condition of children was evaluated on a 10-point scale in accordance with the above ten qualities. During the initial testing, the following results were obtained: Polina $S$. has obtained four points, llya V. -5 points, Farida A. -6 points, and Artem L. - 2 points. Communicative and cognitive abilities of children are presented in Table 1: 
Table 1: Results of testing of communicative, cognitive, musical, and creative skills, and ability to learn in children with DPVD and early childhood autism

\begin{tabular}{lllll}
\hline Results & Polina S. & llya V. & Farida A. & Artem L. \\
\hline Productive activity time & $\sqrt{ }$ & $\sqrt{ }$ & & \\
Ability to concentrate & $\sqrt{ }$ & $\sqrt{ }$ & $\sqrt{ }$ & $\sqrt{ }$ \\
Attentional set-shifting & $\sqrt{ }$ & $\sqrt{ }$ & $\sqrt{ }$ & \\
Speech development & & $\sqrt{ }$ & $\sqrt{ }$ & \\
Understanding spoken language & $\sqrt{ }$ & $\sqrt{ }$ & $\sqrt{ }$ & \\
Ear for music & $\sqrt{ }$ & & & \\
Timekeeping & & & $\sqrt{ }$ & $\sqrt{ }$ \\
Accuracy of intonation & & &
\end{tabular}

At the initial stage of the psychological and pedagogical experiment, testing and supervision of children with health limitations, who have shown low results, were carried out. After a cycle of special classes, almost all indicators were improved, although these indicators of one autistic child were lower than those of the others.

Special vocal skills were also tested. These included singing setting, breathing, sound formation, articulation, and intonation. As a rule, autistic children have a low level of development of these qualities, which had to be improved by folklore-based music therapy. Vocal skills were manifested only by Polina and Farida; llya and Artem could not sing, and in fact, they have acquired vocal skills during the lessons.

Each of the four cases required conducting an analysis of the problems encountered by children in learning, as well as an individual selection of the most appropriate forms of work. Based on the results of the initial testing of children, specific strategy for music lessons was developed for each child.

The most difficult condition was noted in Artem (9 years old): The speech was absent, there were many motor stereotypes, and communicative and cognitive functions were poorly developed. Initially, music classes were held in a test mode once a week for $20 \mathrm{~min}$. The child was very sensitive to sounds, from an early age, he asked to turn off the music if it sounded longer than $10 \mathrm{~min}$. At the beginning of training, Artem vocalized very much on his syllables, he practically did not fall silent, especially vocalizations increased in stressful situations - he was almost shouting.

Artem's parents expected help from music classes in the overall development of the child, in particular, his speech and communication skills. Following their wishes and based on the long-term development program of the child, the indicators were selected, which could be improved, namely:

Increasing the time of productive activity Accelerating of shiftability from one activity to another

Developing speech and communication skills in general

Developing an understanding of oral speech, switching from visual perception to auditory

Developing the musical ear

Developing a sense of rhythm
Learning to play musical instruments

Learning to move to the music

Forming correct vocal attitude

Learning the accuracy of intonation

Forming proper sound formation.

\section{Results}

Classes with children of the center were based on modern art-therapeutic technologies that combined the developing and training potential of game and music teaching methods based on the musical folklore. The program was designed for 1 year, for children aged 3-7 years, which were divided into groups depending on the level of development, possession of various skills, the nature of the pathology, and previous training experience. Advantages of classes in groups at the social center are as follows:

Overcoming the consequences of long-term social deprivation of children, acquiring communication skills by such children

\section{Developing strong-willed efforts}

Inspiring emotionally through collective activity

Shorter-term of skills acquisition to imitate their peers

Applying the greatest number of different exercises to harmonize both the emotional sphere of the individual child and interpersonal interactions in the group.

Lessons were clearly structured in such a way that the psychophysical load on children was evenly distributed. The high result in the course of readaptation and socialization of children with health limitations was achieved through the use by teachers of the Rehabilitation Center of simple songs, which were performed by children during outdoor games. They enabled children with health limitations to form skills of fast movements, dexterity, intelligence, ability to work in a team, and coherence.

Nursery rhymes and jokes are effective for the development of small motor skills in children with health limitations. Other genres of game folklore help to form children's skills of plastic improvisation and consolidate the transfer of artistic image by performing a variety of expressive movements. The children had to fill their movements with emotive expressive pandemic character, vivid facial expressions, and gestures. Thus, when pronouncing and dramatizing nursery rhymes, "I'm sitting on a stone" the children have done all the movements that were appropriate to its content. Practicing teachers emphasized the emotional state of the children in the expressive transmission of the movements of the animals mentioned in the poems. 
Recitation of rhymes or poems was aimed at creating a rhythmic tone, activating the emotional sphere, and overcoming psychological problems. The purpose of the rhythmic exercise games was also to develop a sense of meter and rhythm, acquiring the skill of elementary rhythmic improvisation, inclusion to various forms of musical performance in role-playing games. The simplest music rhythms were mastered in the course of recitation or singing short nursery rhymes, which was accompanied by playing on wooden spoons or tambourines. For their learning, the teacher together with children rhythmically clapped his hands and against this background expressively recited the text. It is advisable to offer children to repeat the text in phrases like echo, especially because the echolalia, as noted by Marom et al., can perform six functions in autistic children, including "echoing as an attempt to initiate or maintain communication" [23]. When the text is remembered, one may add movements: Stepping around the room to the beat, walking along a circle with various options for stops, squats, turns, etc.

The structure of the lesson varied in different groups. Exercises and songs, music for listening, and games changed from lesson to lesson; however, the structure of the lesson remained the same so that the autistic child had a kind of waymark that would help him feel that he owns the situation, it is predictable and, therefore, safe. following:

In the initial testing, attention was paid to the

The length of training sessions, i.e., the time when the child was able to work productively without distraction and falling into auto-stimulation

The ratio of learning time and breaks, the length of the necessary breaks

The ability of the child to switch between different activities

Flexibility in following the lesson plan or rigidity, the need to maintain a single unchanged plan, including training rituals (greeting songs and farewells, etc.)

Ability to maintain contact with the teacher.

After a series of music lessons, these abilities were tested again to assess the effectiveness of the conducted work. The main thing was to monitor the increase in the development level of communication and cognitive skills. During repeated testing (Table 2), the following results were obtained: Polina $S$. got 7 points, Ilya V. -8 points, Farida A. -9 points, and Artem L. -6 points.

Artem has shown the greatest rigidity and susceptibility to stress. Therefore, the contact was not established immediately. The use of vocals was most successful: In the classroom teacher sang Artem songs-nursery rhymes, the boy listened to them and fell silent. After each lesson, he was in a more relaxed and benevolent mood. He was not very interested in musical instruments, although he knew how to use them all - which ones to blow, which ones to knock on, which ones to ring.

Table 2: Results of repeated testing of communicative, cognitive, musical, and creative skills, and ability to learn in children with DPVD and early childhood autism after the training course

\begin{tabular}{lllll}
\hline Results & Polina S. & llya V. & Farida A. & Artem L. \\
\hline Productive activity time & $\sqrt{ }$ & $\sqrt{ }$ & $\sqrt{ }$ & $\sqrt{ }$ \\
Ability to concentrate & $\sqrt{ }$ & $\sqrt{ }$ & $\sqrt{ }$ & $\sqrt{ }$ \\
Attentional set-shifting & $\sqrt{ }$ & $\sqrt{ }$ & $\sqrt{ }$ & $\sqrt{ }$ \\
Speech development & & $\sqrt{ }$ & $\sqrt{ }$ & $\sqrt{ }$ \\
Understanding spoken language & $\sqrt{ }$ & $\sqrt{ }$ & $\sqrt{ }$ & $\sqrt{ }$ \\
Ear for music & $\sqrt{ }$ & $\sqrt{ }$ & $\sqrt{ }$ & $\sqrt{ }$ \\
Timekeeping & $\sqrt{ }$ & & $\sqrt{ }$ & \\
Accuracy of intonation & & $\sqrt{ }$ & $\sqrt{ }$ & $\sqrt{ }$ \\
Ability to play musical instruments & & & &
\end{tabular}

Precision movements to the music

At home, Artem had a synthesizer, to which he showed great interest only in relation to the demo program, which he ran endlessly while producing stereotypical movements. After the music classes began, Artem's behavior changed significantly: He began to study the capabilities of the instrument, listen to individual sounds, scales, switch on different music in different versions, began to change the harmonic accompaniment, tempo, timbres, i.e., began to experiment and study the sound. It was his first productive, independent activity. At the same time, vocalizations almost disappeared, but if they appeared, the teacher used them according to the Floortime technique [6], joining the vocalizations, but singing them with a free vocal sound, which Artem liked very much, he laughed and tried to imitate another method of sound production. During the classes, Artem began to better perceive instructions by ear, before that he really needed visual support provided by card system, after training he began mostly to understand the addressed speech.

The specificity of the lessons with Artem consisted in the need to create a learning environment in which the boy would be concentrated enough for productive activities without distraction and going into self-stimulation. At the same time, he could not be overworked, since in this case, the nervous system was experiencing too much stress, and Artem was losing control over his behavior. At the beginning of classes, Artem was offered nursery rhyme songs. They had to be accompanied by a movement corresponding to the text. However, Artem did not understand the text, and when the assistant helped him to do the right movements, he resisted. Then, the teacher himself hummed a song to Artem, accompanying the singing with sounding gestures and inviting the boy to join. As a result, with a little help, Artem began to accompany the singing with claps. The next stage was instrumental music, which the teacher played on the piano, and Artem was offered folk instruments to accompany it. He was able to join in the joint music-making with a little help.

When Artem began to vocalize in the classroom, the teacher, using the Floortime technique, also began to produce sounds on the same phonemes, but vocal, with 
a certain stable pitch. Octave or fifths jumps often turned out at the sound of "u." Another option: When Artem often repeated "dya-dya-dya," the teacher pronounced a clear "Da" ("Yes!") emotionally and beautifully, so the child also wanted to repeat correctly. This tactic was also successful. Thus, classes with Artem were mostly aimed at the inclusion into joint musical activity and initiation of the speech. Both directions are extremely important at the current stage of its development. Artem's progress was most noticeable exactly in these areas because initially, he had the lowest level of communicative and cognitive abilities.

\section{Discussion}

The results of the study confirm the hypothesis about the capability of music to enhance the development of communicative and cognitive abilities in children with DPVD, as well as in autistic children. All children in the Rehabilitation Center, who were trained in classes, changed the ratio between time of the activity in the classroom and relaxing or distracting activities. Understanding of speech increased significantly and speech skills were partially formed. While at the beginning of the experiment wandering around the class and attempts to establish productive activities took almost half a 30-min lesson, at the end of the experiment, they were reduced to almost a quarter. At that, children became more organized, and starting classes for them was easier. In addition, class time was used more efficiently, although Artem still needed a lot of time to recover, since he distressed using stereotypical movements and vocalizations. However, certain progress was achieved by all autistic children.

An important indicator of development was the switch from visual perception to auditory. Autistic children, who initially did not respond to speech, began to demonstrate an understanding of explanations and instructions, as well as to repeat the words (though only in a whisper). While in the beginning, to go to a music lesson, they had to see a card with a teacher photo, at the end of the cycle of classes, it was enough to say that there would be a music lesson or name the teacher. They began to listen attentively to nursery rhymes songs exactly at music lessons. This experience confirms the idea of scientists that "music therapist transformed the child's verbal and gestural material into interactive music-based games. Musical play experiences may create conditions for the child to explore different ways of being, interacting, and communicating. The child's verbal strengths become the foundation for musicalplay experiences that aim to expand their repertoire of social and relational experience" [26].

The value of the obtained research results in comparison with other studies consists in proving the effectiveness of the use of art-therapeutic and gaming technologies based on folklore to improve the level of communicative and cognitive abilities of children with DPVD and early childhood autism. As noted by the team of authors of the study, "the potential role of rhythmic entrainment and music therapy intervention for individuals with autism spectrum disorders (ASD)," "music and rhythm have shown significant potential in improving the oral-motor activities of people affected by ASD. Music improves their social communication and motor skills," and this work "represents the possible role of rhythmic cueing for sensorimotor regulation in ASD individuals" [21]. Another group of researchers notes that "humanoid social robot systematically teaches music to children with autism to improve social/cognitive skills through active music games," and "noticeable improvements were seen in social/cognitive skills of all participants as well as in the positive effect of this program on fine motor imitation skills" [25].

However, in addition to the regulatory function, music performs the important function of activating the child's brain. Our hypothesis is partly similar to the findings of Canadian scientists who "evaluated the neurobehavioral outcomes of a music intervention on social communication and brain connectivity in school-age children," and their study "provides the first evidence that 8-12 weeks of individual music intervention can indeed improve social communication and functional brain connectivity" [24]. However, unlike previous practices of music therapy, the present experiment proves the possibility of forming not only the key capabilities for the development of communicative and cognitive abilities in children with DPVD and early autism, such as the time of productive activity; the ability to concentrate; attentional set-shifting; speech development; and understanding of oral speech but also complex creative abilities such as musical ear, sense of rhythm, and the ability to play instruments, which are acquired in the course of special training. The learning ability of autistic children to music, which can be used not only for the purpose of positive emotional impact, was proved experimentally [30]. As a means of communication that gives autistic children a sense of trust and peace of mind, music removes restrictions in the social, and emotional interaction of special children with parents, doctors, and teachers that increase the effectiveness of the treatment of such patients and their training in basic skills in the field of musical performance.

The pedagogical experiment also allowed determining the peculiarities of application of arttherapeutic and gaming technologies, contributing to their effectiveness in the course of rehabilitation and socialization of children with health limitations. As it was found out, in the teaching of singing children's folk songs, a child with health limitations goes through several stages, first mastering basic skills, and then acquiring more complex and special attainments. 
Therefore, it is worth using different techniques and adjusting them at different stages: At the first stage, it is advisable to apply corrective programs related to music therapy, at the second stage - special vocal techniques. Since children, who receive initial musical skills, are usually still small, it is necessary to include in the lessons playing methods, which then can contribute to mastering complicated skills. The significance of the study lies in the fact that the analysis of the applied methods used when working with children with health limitations at different stages of their education, and the choice of the most effective method can help a budding specialist to build a correct strategy of the educational process, and be ready to correct the arising problems. The scientific novelty of the research results is that vocal training, as shown by the psychological and pedagogical experiment, has an advantage over learning to play musical instruments since the voice is the instrument closest to the child, which is directly related to speech. Improvement of vocal skills leads to the improvement of speech. Work with autistic children has proved that music folklore activities contribute to the development of not only singing or verbal but also communicative and cognitive skills that improve the condition of children and their standard of living, as well as opens up wider prospects in the education of autistic children and the possible acquisition of initial professional skills, in particular in the field of musical creativity.

\section{Conclusion}

As shown by the international pedagogical practice, the effectiveness of development and successful socialization in the environment of children with health limitations is influenced by the process of comprehensive education, which is based on the active play activities of the child. In terms of effectiveness, the game has an exceptional impact on the person who consistently passes through all age stages of the development. The importance of folklore as an important part of the formation process of socialization skills of a child with health limitations is well known and generally recognized. It is confirmed by the present experiment as well. Musical folklore contains kind of needs, which are the main in the course of readaptation and socialization in terms of physical, mental, the moral education of a child with health limitations, that is, personality traits that allow growing up a fully developed person. The principle of influence of ancient folk songs consists in a special melodic and rhythmic structure, esthetic beauty, and emotional-figurative diversity. Based on narrowvolume frets and smooth, often wave-like movement, it harmonizes the external and internal world of a child, leading his soul to a coherent system. Moreover, when the tempo accelerates and slows down during the song, this change in tension and relaxation causes a positive effect in muscle work. Chronic muscle tension is removed due to these differences.

The early start of corrective training provides the greatest efficiency in the correction of a certain defect, which is associated with a high level of plasticity of the brain and nervous system in children. Twothirds of the wards, for whom the training methods were chosen correctly at an early age, acquire a state of a healthy person, i.e. begin to live a normal life, learn similarly as their healthy peers, and previously diagnosed health problems are left in the past. Perhaps in some children with health limitations, problems will remain for life, despite the improvement due to music therapy. However, the level and quality of their lives will still be much higher than they could have been without any intervention. Therefore, it is necessary to start corrective classes as soon as possible, immediately after the diagnosis is made. At that, the organization of early musical development programs, which has proved in other countries to be very effective, should be one of the priorities when helping children with health limitations in Russia. In case of severe health problems in children, highly qualified specialists are required, who must constantly study together with children, adapt to their needs, and try new correction methods.

The effectiveness of correctional work with special children largely depends on taking into account the peculiarities of their learning and development, as well as special educational conditions for children with health limitations. This is associated with the following requirements:

It is necessary to provide a sufficiently comfortable and safe environment, in which the child would be able to successfully carry out his activities

Classes should be conducted in small groups or individually

The study room should be well soundproofed, and it should not contain distracting objects, toys, pictures, etc.

Lessons should be carried out in a very friendly and benevolent atmosphere, where the child will feel safe

The duration of classes should depend on the capabilities of each child, and the active phases of classes must necessarily alternate with pauses, during which the child can relax, as a rule, move around, walk around the class, which requires some space

It is necessary to engage in those types of musical and creative activities, which are desired by the children: One is allowed singing, the other is interested in playing instruments, while the third prefers to make music with a teacher. 


\section{Acknowledgments}

The article is prepared within the framework of research work on the topic: "Features of the use of arttherapeutic and gaming technologies in the course of rehabilitation and socialization of children with health limitations based on the traditional Russian folklore," carried out with the financial support of the Russian State Social University.

\section{References}

1. Kopytin Al. Osnovy Art-terapii. United States: Izd-vo "Lan"; 1999.

2. Decker-Voigh G. An Introduction to Music Therapy. New York, United States: SAGE Publications Ltd.; 2003.

3. Lazarev M. System of Developmental Therapy for Children with Asthma. Moscow: Rehabilitation Center for Children; 1993.

4. Glozman ZH, Pavlov A. The influence of musical studies on the development of spatial and kinetic functions in children of primary school age. Psychol Sci Educ. 2007;3:35-46.

5. Kotysheva E. Musical psychological correction in the course of rehabilitation of children with health limitations. Omsk Sci Bull. 2009;2:179-83

6. Greenspan $\mathrm{S}$, Weeder $\mathrm{S}$. On a first-name basis with autism. In: Using Floortime Methodology to Develop Relationships, Communication, and Thinking. Moscow: Terevinf; 2013

7. Korolkova E. Music Lessons as a Means of Correctional Development in the Education and Upbringing of Children with Health Limitations. Kazan: In Proceedings of the $4^{\text {th }}$ International Scientific Conference on Innovative Pedagogical Technologies; 2016. p. 87-90

8. Petrushin VI. Muzykalnaya Psihoterapiya. Singapore: Book on Demand Ltd.; 2000.

9. Gudina T. Musical education of younger schoolchildren with DPVD. Educ Train Child Dev Disabil. 2006;1:28-31.

10. Rybakova S. Art Therapy for Children with Mental Retardation: A Training Manual. St. Petersburg, Publishing House Rech; 2007.

11. Boromykova O. Correction of Speech and Movement with Music. St. Petersburg: Detstvo-Press; 1999.

12. Edgerton $\mathrm{C}$. The effect of music therapy on the communicative behaviors of autistic children. J Music Ther. 1994;31(1):31-62. https://doi.org/10.1093/jmt/31.1.31

13. Johnston D, Egermann H, Kearney G. Innovative computer technology in music-based interventions for individuals with autism moving beyond traditional interactive music therapy techniques. Cogent Psychol. 2018;5(1):1-18. https://doi. org/10.1080/23311908.2018.1554773

14. Udovina-Galperina T. At the Piano Without Crying, or I Am a
Children's Educator. St. Petersburg: Union of Artists; 2002.

15. Davydova A, Pereverzeva M, Tsarev D, Shcherbakova A Shcherbinina V. Musical art-therapeutic technologies of overcoming psychological problems and developing the emotional perception of children. J Pharm Sci Res. 2018;10(4):846-8.

16. Ovsyannikova V, Grigorieva E, Katz M, Morozova E, Scherbinina V. Art-therapeutic technologies based on musical folklore forwarded to overcome psychological problems. Opcion. 2018;34(17):206-23.

17. Vinogradov GS. Izdanie irkutskoj sekcii naučnyh rabotnikov. In Russkij Detskij Folklor. USA: LENAND; 1930.

18. Alvin J, Warwick A. Music Therapy for the Autistic Child. New York: Oxford University Press; 2008.

19. Nektu ZH. Sound therapy workshop (French experience in music and dance therapy). Children with special needs. Res Exp Help. 2001;4:61-77.

20. Permyakova M, Tkachenko E. Vliyanie zanyatij muzykoj na kognitivnoe razvitie detej mladshego shkolnogo vozrasta. Educ Sci. 2016;4(133):155-70

21. Bharathi G, Jayaramayya $K$, Balasubramanian V, Vellingiri $E$. The potential role of rhythmic entrainment and music therapy intervention for individuals with autism spectrum disorders. J Exerc Rehabil. 2019;15(2):180-6. https://doi.org/10.12965/ jer.1836578.289 PMid:31110998

22. Brown S. Autism and music therapy: Is change possible, and why music? J Br Music Ther. 1994;8(1):15-25. https://doi. org/10.1177/135945759400800105

23. Marom M, Gilboa A, Bodner E. Musical features and interactional functions of echolalia in children with autism within the music therapy dyad. Nord J Music Ther. 2018;27(3):175-96. https:// doi.org/10.1080/08098131.2017.1403948

24. Sharda M, Tuerk C, Chowdhury R, Jamey K, Foster N, CustoBlanch $\mathrm{M}$, et al. Music improves social communication and auditory-motor connectivity in children with autism. Transl Psychiatry. 2018;8(1):231. https://doi.org/10.31234/osf. io/2xnmv

\section{PMid:30352997}

25. Taheri A, Meghdari A, Alemi M, Pouretemad H. Teaching music to children with autism: A social robotics. Sci Iran. 2019;26(1):40-58. https://doi.org/10.24200/sci.2017.4608

26. Thompson G, Elefant C. But I want to talk to you? Perspectives on music therapy practice with highly verbal children on the autism spectrum. Nord J Music Ther. 2019;28(4):347-59. https:// doi.org/10.1080/08098131.2019.1605616

27. Vladić-Mandarić L, Plosko A. The effects of music in music therapy on autistic children. Sci Art Cult. 2017;4:138-46.

28. Woodward A. Music therapy for autistic children and their families: A creative spectrum. Br J Music Ther. 2004;18(1):8-14. https://doi.org/10.1177/135945750401800103

29. Perkins. A Guide to Teaching Children with Visual Impairment and Multiple Developmental Disorders. Part 1. Methodical Bases. Moscow: Center of Medical Pedagogy, Perkins; 2011.

30. Tishina E. Muzykalnoe vospitanie kak sredstvo socialnoj adaptacii mladshih shkolnikov s zaderzhkoj psihicheskogo razvitiya. Pedagog Educ Sci. 2007;2:23-4. 